\title{
Qualitative analysis of 7- and 8-hydroxyzolpidem and discovery of novel zolpidem metabolites in postmortem urine using liquid chromatography-tandem mass spectrometry
}

\author{
Koji Yamaguchi ${ }^{1}$ (D) Hajime Miyaguchi ${ }^{2} \cdot$ Youkichi Ohno $^{1} \cdot$ Yoshimasa Kanawaku$^{1}$
}

Received: 11 September 2021 / Accepted: 19 November 2021 / Published online: 4 January 2022

(c) The Author(s) 2021

\begin{abstract}
Purpose Zolpidem (ZOL) is a hypnotic sometimes used in drug-facilitated crimes. Understanding ZOL metabolism is important for proving ZOL intake. In this study, we synthesized standards of hydroxyzolpidems with a hydroxy group attached to the pyridine ring and analyzed them to prove their presence in postmortem urine. We also searched for novel ZOL metabolites in the urine sample using liquid chromatography-triple quadrupole mass spectrometry (LC-QqQMS) and liquid chromatography-quadrupole time-of-flight mass spectrometry (LC-QqTOFMS).

Methods 7- and 8-Hydroxyzolpidem (7OHZ and 8OHZ, respectively) were synthesized and analyzed using LC-QqQMS. Retention times were compared between the synthetic standards and extracts of postmortem urine. To search for novel ZOL metabolites, first, the urine extract was analyzed with data-dependent acquisition, and the peaks showing the characteristic fragmentation pattern of ZOL were selected. Second, product ion spectra of these peaks at various collision energies were acquired and fragments that could be used for multiple reaction monitoring (MRM) were chosen. Finally, MRM parameters were optimized using the urine extract. These peaks were also analyzed using LC-QqTOFMS.

Results The presence of $7 \mathrm{OHZ}$ and $8 \mathrm{OHZ}$ in urine was confirmed. The highest peak among hydroxyzolpidems was assigned to 7OHZ. The novel metabolites found were zolpidem dihydrodiol and its glucuronides, cysteine adducts of ZOL and dihydro(hydroxy)zolpidem, and glucuronides of hydroxyzolpidems.

Conclusions The presence of novel metabolites revealed new metabolic pathways, which involve formation of an epoxide on the pyridine ring as an intermediate.
\end{abstract}

Keywords Zolpidem · Structural elucidation · LC-QqQMS · LC-QqTOFMS · Dihydrodiol · Cysteine adducts

\section{Introduction}

Hypnotics are used to treat insomnia, but they are sometimes involved in drug-facilitated crimes including sexual assaults, homicides, and robberies. In such cases, forensic toxicologists are asked to analyze the hypnotics and/or their metabolites in body fluids, such as blood, urine, and saliva, obtained from a victim. Understanding the metabolism of hypnotics is necessary for demonstrating misuse. In

Koji Yamaguchi

yamakoji@nms.ac.jp

1 Department of Legal Medicine, Nippon Medical School, 1715 Kamagari, Inzai, Chiba 270-1694, Japan

2 National Research Institute of Police Science, 6-3-1 Kashiwanoha, Kashiwa, Chiba 277-0882, Japan addition, information about drug intake can be obtained; for example, the time interval after drug intake can be estimated from concentration ratios of hypnotic metabolites. Forsman et al. investigated urinary excretion patterns of flunitrazepam and its metabolites, and concluded that the ratio of 7-aminodesmethylflunitrazepam to 7-aminoflunitrazepam may be used to estimate the time of intake [1]. Tsujikawa et al. examined the urinary excretion patterns of triazolam metabolites and found that the ratio of $\alpha$-hydroxytriazolam to 4-hydroxytriazolam were decreased over time [2]. Feng et al. analyzed zolpidem (ZOL) and its major metabolite (M1) in oral fluid and found that ZOL/M1 ratio decreased after ZOL intake [3]. These studies demonstrated the usefulness of analysis of hypnotic metabolites. However, prior to studies about concentrations of hypnotic metabolites in human body fluids, identification of hypnotic metabolites and preparation of their analytical standards are required. 
In the past few decades, liquid chromatography-tandem mass spectrometry (LC-MS/MS) utilizing the triple quadrupole (QqQ) and quadrupole-time-of-flight (QqTOF) analyzers has become widely used in forensic toxicological analysis because of its excellent selectivity and sensitivity $[4,5]$. Now drug metabolites can be found that are produced from only a small fraction of an administered drug. By applying these technologies, novel metabolites not known at the time of launch can be discovered even for well-known hypnotics, such as Z-drugs (ZOL, and zopiclone) and benzodiazepines. Novel metabolites can show different characteristics in the time courses of blood concentration, distribution, and excretion, and these findings enable further understanding of drug metabolism. For example, we previously found novel quazepam metabolites in human bile and revealed that some of them accumulate in bile at extremely high concentrations [6].

ZOL is a short-acting hypnotic and is the most widely used prescription drug for sleep disorders in the Unites States [7]. Accordingly, the analysis of ZOL and its metabolites in biological samples is a major concern in forensic toxicology. The metabolism of ZOL, reported from a study in the drug development process, is illustrated in Fig. 1 [8]. In our previous work, we developed a synthetic method for ZOL metabolites and successfully synthesized M1-M4 [9]. We also analyzed ZOL metabolites in human blood and urine using LC-QqQMS, and revealed the presence of an unknown metabolite, which is a hydroxyzolpidem with a hydroxy group on the pyridine ring. However, the exact location of the hydroxy group could not be elucidated by LC-QqQMS alone. There are three possible locations, namely, the 5-, 7-, and 8-positions as depicted in Fig. 1. In this study, we elucidated the exact location of the hydroxy group by synthesizing standards of hydroxyzolpidems. We also searched for novel ZOL metabolites in postmortem urine using LC-QqQMS and LC-QqTOFMS.

\section{Materials and methods}

\section{Reagents}

$N, N$-Dimethylpropiolamide (DMPA, IUPAC name: $N, N$ dimethylprop-2-ynamide) was synthesized as described previously [9]. The precursor materials for the synthesis of 7-methoxyzolpidem (7OMeZ) and 8-benzyloxyzolpidem (8OBzZ), 2-amino-4-methoxy-5-methylpyridine (1) and 2-amino-3-benzyloxy-5-methylpyridine (2), respectively, were synthesized in this study. The details of synthesis are presented in the supplementary information. Pyrrolidine and $1 \mathrm{~mol} / \mathrm{L}$ methylene chloride solution of boron tribromide $\left(\mathrm{BBr}_{3}\right)$ were purchased from Tokyo Chemical Industry Co. Ltd. (Tokyo, Japan). Copper(I) chloride $(\mathrm{CuCl})$, copper(II) triflate $\left(\mathrm{Cu}(\mathrm{OTf})_{2}\right), 0.1 \mathrm{~mol} / \mathrm{L}$ phosphate buffer (pH 6), molecular sieves 4A, and $\mathrm{NH}_{2}$ silica gel (Wakogel, $50 \mathrm{NH}_{2}$ ) were purchased from Fujifilm Wako Pure Chemical Co. (Osaka, Japan). $\beta$-Glucuronidase (from Escherichia coli., type IX-A) was purchased from Sigma-Aldrich (St. Louis, MO). Other chemicals were purchased from Kanto Chemical Co., Inc. (Tokyo, Japan).
Fig. 1 Metabolic pathway of ZOL

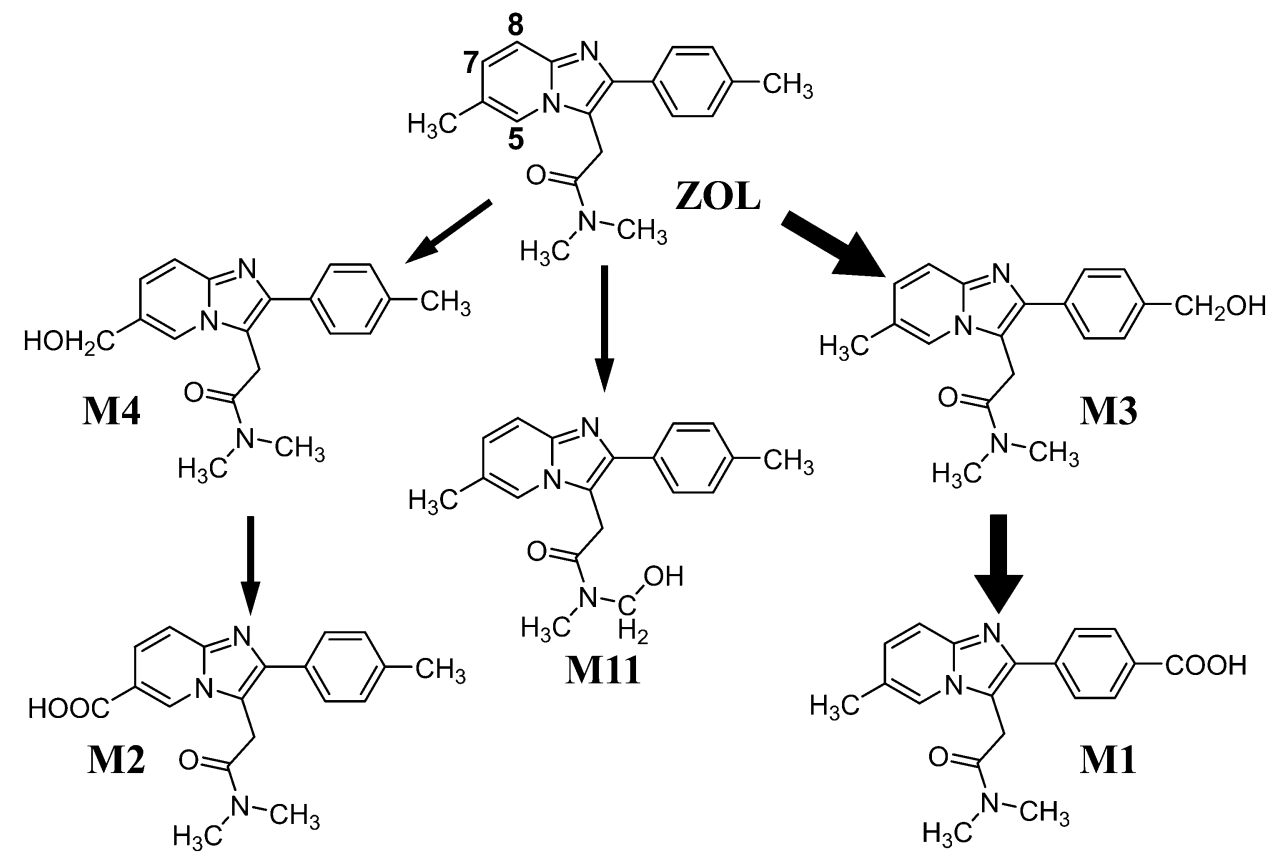




\section{Nuclear magnetic resonance spectroscopy}

${ }^{1} \mathrm{H}$ and ${ }^{13} \mathrm{C}$ nuclear magnetic resonance (NMR) spectra were recorded using an Avance III HD 400 (Brucker Co., Billerica, MA) or ECA-600 (JEOL Ltd., Tokyo, Japan) spectrometer. Chemical shifts were referenced to the tetramethylsilane (TMS) signal at $\delta=0 \mathrm{ppm}$ in chloroform- $d$ $\left(\mathrm{CDCl}_{3}\right)$ or to the residual solvent signals at $\delta=2.50$ and $39.52 \mathrm{ppm}$ in dimethylsulfoxide- $d_{6}\left(\mathrm{DMSO}-d_{6}\right)$ for ${ }^{1} \mathrm{H}$ and ${ }^{13} \mathrm{C}$ NMR spectra, respectively. All NMR spectra of the compounds synthesized in this study are presented in the supplementary information.

\section{High-resolution mass spectrometry for synthesized compounds}

High-resolution mass spectrometry (HR-MS) measurements for synthesized compounds were performed using a Q Exactive mass spectrometer (Thermo Fisher Scientific, Waltham, MA) with an electrospray ionization (ESI) probe. Full scan mass spectra were recorded in positive mode. The conditions for ESI were as follows: sheath gas flow rate, 5 units; capillary temperature, $320{ }^{\circ} \mathrm{C}$; spray voltage, $3.5 \mathrm{kV}$; probe heater temperature, $350{ }^{\circ} \mathrm{C}$; S-lens RF level, 50 units. Products were dissolved in a 1:1 $(\mathrm{v} / \mathrm{v})$ mixture of water-acetonitrile containing $0.1 \%$ formic acid at a concentration of $1 \mu \mathrm{g} / \mathrm{mL}$ and infused into the spectrometer at a flow rate of $10 \mu \mathrm{L} / \mathrm{min}$.

\section{General procedure of the modified three-component coupling reaction}

A three-component coupling reaction was performed using a previously reported procedure with modification [9]. Molecular sieves 4A ( $2 \mathrm{~g}$ ), 4-methylbenzaldehyde (2 mmol), 2-aminopyridine (1 or $2,2 \mathrm{mmol}$ ), chloroform $(4 \mathrm{~mL})$, and pyrrolidine $(0.2 \mathrm{mmol})$ were placed in a $30 \mathrm{~mL}$ screw vial. The mixture was sealed and heated at $100{ }^{\circ} \mathrm{C}$ for $3 \mathrm{~h}$. After cooling to room temperature, $\mathrm{CuCl}$ $(0.4 \mathrm{mmol}), \mathrm{Cu}(\mathrm{OTf})_{2}(0.4 \mathrm{mmol})$, and DMPA $(3.6 \mathrm{mmol})$ were added. The vial was sealed again and heated at $80{ }^{\circ} \mathrm{C}$ for $3 \mathrm{~h}$. After removing the molecular sieves by filtration, ammonia $(28 \%, 0.4 \mathrm{~mL})$ was added to the solution and the mixture was stirred at room temperature for $10 \mathrm{~min}$. The mixture was passed through an $\mathrm{NH}_{2}$ silica gel column ( $3 \mathrm{~cm}$ [i.d.] $\times 1 \mathrm{~cm}$ [height]), and the column was washed with chloroform $(30 \mathrm{~mL})$. The solvent was removed by evaporation and the product was purified by silica gel column chromatography (eluent: chloroform-ethyl acetate $1: 1$ for $7 \mathrm{OMeZ}$ and $3: 1$ for $8 \mathrm{OBzZ}$ ). Recrystallization from ethyl acetate-diisopropyl ether for $7 \mathrm{OMeZ}$ and chloroform-ethyl acetate for $8 \mathrm{OBzZ}$ gave the desired products as white crystals.

7OMeZ: Yield 44\%. ${ }^{1} \mathrm{H}$ NMR (400 MHz, $\left.\mathrm{CDCl}_{3}\right) \delta 2.21$ (s, 3H), 2.40 (s, 3H), $2.86(\mathrm{~s}, 3 \mathrm{H}), 2.94(\mathrm{~s}, 3 \mathrm{H}), 3.88(\mathrm{~s}, 3 \mathrm{H})$, $4.07(\mathrm{~s}, 2 \mathrm{H}), 6.90(\mathrm{~s}, 1 \mathrm{H}), 7.25(\mathrm{~m}, 2 \mathrm{H}), 7.54(\mathrm{~m}, 2 \mathrm{H}), 7.96$ (s, 1H). ${ }^{13} \mathrm{C}$ NMR (151 MHz, $\left.\mathrm{CDCl}_{3}\right) \delta 14.00,21.28,30.40$, 35.86, 37.52, 55.47, 93.61, 112.08, 116.14, 123.11, 128.27, $129.32,132.14,137.17,142.80,146.15,157.47,168.65$. Elemental analysis calcd for $\mathrm{C}_{20} \mathrm{H}_{23} \mathrm{~N}_{3} \mathrm{O}_{2}: \mathrm{C} 71.19 \%, \mathrm{H} 6.87 \%$, N $12.45 \%$; found: C $70.72 \%, \mathrm{H} 6.95 \%, \mathrm{~N} 12.02 \%$. HR-MS: calcd for $\mathrm{C}_{20} \mathrm{H}_{24} \mathrm{~N}_{3} \mathrm{O}_{2}\left([\mathrm{M}+\mathrm{H}]^{+}\right)$338.1863; found 338.1855.

8OBzZ: Yield 42\%. ${ }^{1} \mathrm{H}$ NMR $\left(400 \mathrm{MHz}, \mathrm{CDCl}_{3}\right) \delta 2.26$ (s, 3H), 2.39 (s, 3H), 2.87 (s, 3H). $2.94(\mathrm{~s}, 3 \mathrm{H}), 4.07$ (s, 2H), $5.35(\mathrm{~s}, 2 \mathrm{H}), 6.35(\mathrm{~s}, 1 \mathrm{H}), 7.24(\mathrm{~m}, 2 \mathrm{H}), 7.2-7.5(\mathrm{~m}, 5 \mathrm{H})$, $7.56(\mathrm{~m}, 2 \mathrm{H}), 7.66(\mathrm{~s}, 1 \mathrm{H}) .{ }^{13} \mathrm{C} \mathrm{NMR}\left(151 \mathrm{MHz}, \mathrm{CDCl}_{3}\right) \delta$ 18.96, 21.29, 30.60, 35.86, 37.49, 70.58, 106.29, 114.65, $115.45,121.66,127.26,127.88,128.55,128.76,129.19$, $131.92,136.63,137.28,138.70,143.26,147.10,168.40$. Elemental analysis calcd for $\mathrm{C}_{26} \mathrm{H}_{27} \mathrm{~N}_{3} \mathrm{O}_{2}$ : C 75.52\%, H 6.58\%, $\mathrm{N} 10.16 \%$; found: C $75.31 \%$, H 6.66\%, N 10.06\%. HR-MS: calcd for $\mathrm{C}_{26} \mathrm{H}_{28} \mathrm{~N}_{3} \mathrm{O}_{2}\left([\mathrm{M}+\mathrm{H}]^{+}\right)$414.2176; found 414.2168.

\section{Synthesis of $70 \mathrm{HZ}$ hydrobromide}

7OMeZ (337 mg, $1.00 \mathrm{mmol}$ ) was dissolved in chloroform $(4 \mathrm{~mL})$ and then $1 \mathrm{~mol} / \mathrm{L} \mathrm{BBr}_{3}$ solution $(4 \mathrm{~mL})$ was added. The mixture was heated at $60{ }^{\circ} \mathrm{C}$ and stirred for $15 \mathrm{~h}$. Acetonitrile containing $20 \%(v / v)$ of water $(5 \mathrm{~mL})$ was added and the mixture was stirred for $10 \mathrm{~min}$ at room temperature. The reaction mixture was evaporated to dryness. The product was purified by column chromatography (silica gel, eluent: chloroform-ethanol-formic acid 90:10:1). The fractions containing the desired product were pooled and evaporated. The desired product was recrystallized from isopropanolwater as white crystals. Yield $0.264 \mathrm{~g}(0.652 \mathrm{mmol}, 65 \%)$. ${ }^{1} \mathrm{H}$ NMR (400 MHz, DMSO- $\left.d_{6}\right) \delta 2.23(\mathrm{~s}, 3 \mathrm{H}), 2.39(\mathrm{~s}, 3 \mathrm{H})$, $2.90(\mathrm{~s}, 3 \mathrm{H}), 3.13(\mathrm{~s}, 3 \mathrm{H}), 4.20(\mathrm{~s}, 2 \mathrm{H}), 7.05(\mathrm{~s}, 1 \mathrm{H}), 7.42(\mathrm{~m}$, 2H,), 7.45 (m, 2H), 8.52 (s, 1H,), 12.10 (brs, 1H), 13.70 (brs, 1H). ${ }^{13} \mathrm{C}$ NMR (151 MHz, DMSO- $\left.d_{6}\right) \delta 13.09,20.86,28.07$, $35.32,36.95,91.42,116.35,119.60,124.19,126.48,127.75$, 129.96, 130.87, 139.59, 140.43, 161.52, 166.96. Elemental analysis calcd for $\mathrm{C}_{19} \mathrm{H}_{22} \mathrm{BrN}_{3} \mathrm{O}_{2}$ : C $56.44 \%, \mathrm{H} 5.48 \%, \mathrm{~N}$ $10.39 \%$; found: C $56.27 \%$, H 5.32\%, N 10.20\%. HR-MS: calcd for $\mathrm{C}_{19} \mathrm{H}_{22} \mathrm{~N}_{3} \mathrm{O}_{2}\left([\mathrm{M}+\mathrm{H}]^{+}\right)$324.1707; found 324.1700.

\section{Synthesis of $80 \mathrm{HZ}$ tosylate}

8OBzZ (209 mg, $0.505 \mathrm{mmol}$ ) was dissolved in chloroform $(2 \mathrm{~mL})$, mixed with $\mathrm{BBr}_{3}$ solution $(2 \mathrm{~mL}, 2 \mathrm{mmol})$, heated at $60{ }^{\circ} \mathrm{C}$, and stirred for $15 \mathrm{~h}$. The mixture was hydrolyzed as described in the synthesis of $7 \mathrm{OHZ}$. The mixture was neutralized with saturated aqueous sodium bicarbonate and evaporated to dryness. The desired product was purified 
by column chromatography $\left(\mathrm{NH}_{2}\right.$ silica gel, eluent: chloroform-ethanol 5:1), and fractions containing the desired product were pooled, mixed with $p$-toluene sulfonic acid monohydrate (122 mg, $0.641 \mathrm{mmol}$ ), and evaporated to dryness. Recrystallization from acetonitrile-ethyl acetate afforded white crystals. Yield $100 \mathrm{mg}(0.203 \mathrm{mmol}, 40 \%)$. ${ }^{1} \mathrm{H}$ NMR (400 MHz, DMSO- $d_{6}$ ) $\delta 2.28(\mathrm{~s}, 3 \mathrm{H}), 2.38(\mathrm{~s}, 3 \mathrm{H})$, $2.40(\mathrm{~s}, 3 \mathrm{H}), 2.90(\mathrm{~s}, 3 \mathrm{H}), 3.12(\mathrm{~s}, 3 \mathrm{H}), 4.21(\mathrm{~s}, 2 \mathrm{H}), 7.06$ (s, 1H), 7.08-7.12 (m, 2H), 7.39-7.42 (m, 2H) 7.46-7.50 (m, 4H), 8.09 (s, 1H,), 12.01 (brs, 1H), 14.78 (brs, 1H). ${ }^{13} \mathrm{C}$ NMR $\left(100 \mathrm{MHz}, \mathrm{DMSO}-d_{6}\right) \delta 17.88,20.75,20.91$, $28.42,35.33,36.96,115.14,115.86,118.81,123.72,125.47$, $127.42,128.03,128.65,129.72,132.05,133.20,137.64$, $139.85,142.22,145.64,166.80$. Elemental analysis calcd for $\mathrm{C}_{26} \mathrm{H}_{29} \mathrm{~N}_{3} \mathrm{O}_{5} \mathrm{~S}$ : C $63.01 \%, \mathrm{H} 5.90 \%, \mathrm{~N} 8.48 \%$; found: $\mathrm{C}$ $62.95 \%, \mathrm{H} 5.96 \%, \mathrm{~N} 8.37 \%$. HR-MS: calcd for $\mathrm{C}_{19} \mathrm{H}_{22} \mathrm{~N}_{3} \mathrm{O}_{2}$ $\left([\mathrm{M}+\mathrm{H}]^{+}\right) 324.1707$; found 324.1701.

\section{Urine sample}

The deceased was a man in his eighties and a victim of fire. He had been prescribed Myslee ${ }^{\circledR} 5 \mathrm{mg}$ tablets containing $5 \mathrm{mg}$ of ZOL tartrate per tablet about 2 weeks before his death. The deceased's urine and heart blood were collected during a medico-legal autopsy. The cause of death was carbon monoxide poisoning; the carboxyhemoglobin saturation in the heart blood was more than $75 \%$ using Avoximeter 4000 oximeter (International Technidyne Co., Edison, NJ). The results of our routine drug screening analysis revealed that the ZOL concentration in the heart blood was at the therapeutic level $(61 \mathrm{ng} / \mathrm{mL})$.

\section{Sample pretreatment}

The urine $(400 \mu \mathrm{L})$ was mixed with $0.1 \%$ formic acid-acetonitrile $(800 \mu \mathrm{L})$ and centrifuged $(6800 \times g, 5 \mathrm{~min})$. The supernatant was evaporated under a nitrogen stream at $40{ }^{\circ} \mathrm{C}$. The residue was dissolved in methanol $(100 \mu \mathrm{L})$, mixed with water $(100 \mu \mathrm{L})$, and centrifuged $(6800 \times g, 5 \mathrm{~min})$. The supernatant was transferred to a vial and $10 \mu \mathrm{L}$ aliquots were injected into the LC-QqQMS and LC-QqTOFMS systems.

\section{LC-QqQMS conditions}

LC-QqQMS analysis was performed using a Nexera XR high-performance liquid chromatograph (Shimadzu Co., Kyoto, Japan) equipped with an LCMS-8040 mass spectrometer (Shimadzu Co.). Chromatographic separation was achieved on an InertSustain C18 column (length $250 \mathrm{~mm}$, i.d. $2.1 \mathrm{~mm}$, particle size $3 \mu \mathrm{m}$; GL Sciences Inc., Tokyo, Japan) at $40{ }^{\circ} \mathrm{C}$. The mobile phase consisted of $10 \mathrm{mM}$ aqueous ammonium formate (A) and methanol (B) at a flow rate of $0.3 \mathrm{~mL} / \mathrm{min}$. The gradient program was as follows: linear gradient from 10 to $40 \% \mathrm{~B}$ at $0-3 \mathrm{~min}$, from 40 to $50 \% \mathrm{~B}$ at 3-18 min, from 50 to $70 \% \mathrm{~B}$ at $18-25 \mathrm{~min}$, from 70 to $98 \%$ $\mathrm{B}$ at $25-26 \mathrm{~min}$, isocratic elution at $98 \% \mathrm{~B}$ at $26-30 \mathrm{~min}$, re-equilibration with $10 \% \mathrm{~B}$ for $5 \mathrm{~min}$. The total runtime was 35 min. Ionization was performed with ESI in positive mode. The conditions for ESI were as follows: nebulizer gas flow rate, $3 \mathrm{~L} / \mathrm{min}$; drying gas flow rate, $15 \mathrm{~L} / \mathrm{min}$; desolvation line temperature, $250{ }^{\circ} \mathrm{C}$; heating block temperature, $400{ }^{\circ} \mathrm{C}$; and source voltage, $5 \mathrm{kV}$. Product ion scan mode was applied to acquire product ion spectra of $7 \mathrm{OHZ}$ and 8OHZ with precursor ion $\mathrm{m} / \mathrm{z} 324.30$, collision energies (CEs) $15,35,55$, and $75 \mathrm{~V}$, and scan range $\mathrm{m} / \mathrm{z}$ 10-340. Multiple reaction monitoring (MRM) mode was applied to analyze ZOL, M1, M2, and hydroxyzolpidems, and the parameters are listed in Table 1.

To search for ZOL metabolites, first, data-dependent acquisition (DDA) mode was applied. The scan range of the trigger scan was $m / z, 100-800$. Product ion spectra were acquired at a CE of $35 \mathrm{~V}$ over $\mathrm{m} / \mathrm{z}, 20-800$. All product ion spectra acquired were checked and peaks that showed characteristic fragmentation patterns (loss of $\mathrm{NMe}_{2}$ and $\mathrm{NMe}_{2} \mathrm{CO},-45$ and $-73 \mathrm{Da}$, respectively) were selected. Second, these peaks were analyzed by product ion scan mode with various CEs $(15,35,55$, and $75 \mathrm{~V})$. Fragment ions with higher intensities were chosen, and finally, MRM parameters for those transitions were optimized by injecting the urine extract. Parameters for the new metabolites (A-E) are listed in Table 2.

\section{LC-QqTOFMS conditions}

LC-QqTOFMS analysis was performed using a Nexera X3 high-performance liquid chromatograph (Shimadzu Co.) equipped with an LCMS-9030 mass spectrometer (Shimadzu Co.). Chromatographic separation was carried out by applying the same conditions of those for LC-QqQMS

Table 1 Parameters of precursor ions, product ions, and CEs in MRM mode for ZOL, M1 and M2, and hydroxyzolpidems

\begin{tabular}{llll}
\hline Analytes & $\begin{array}{l}\text { Precursor } \\
\text { ions }(\mathrm{m} / \mathrm{z})\end{array}$ & Product ions $(\mathrm{m} / \mathrm{z})$ & $\mathrm{CE}(\mathrm{V})$ \\
\hline ZOL & \multirow{2}{*}{308.10} & 235.10 & 36 \\
& & 236.15 & 30 \\
& & 263.15 & 27 \\
M1 and M2 & 338.20 & 265.10 & 38 \\
& & 293.10 & 28 \\
Hydroxyzolpidems & 324.30 & 266.15 & 30 \\
& & 251.20 & 36 \\
& & 279.15 & 25 \\
& & 252.15 & 14 \\
\hline
\end{tabular}

$C E$ collision energy, MRM multiple reaction monitoring 
Table 2 Precursor ions, product ions, and CEs in MRM mode, and scan ranges in product ion scan mode for peaks A-E

\begin{tabular}{|c|c|c|c|c|c|}
\hline \multirow[t]{2}{*}{ Peak } & \multirow{2}{*}{$\begin{array}{l}\text { Precursor } \\
\text { ions }(\mathrm{m} / \mathrm{z})\end{array}$} & \multicolumn{2}{|c|}{ MRM mode } & \multirow{2}{*}{$\begin{array}{l}\text { Product ion scan } \\
\text { mode } \\
\text { Scan ranges } \\
(\mathrm{m} / \mathrm{z})\end{array}$} & \multirow[t]{2}{*}{ Assignment } \\
\hline & & $\begin{array}{l}\text { Product } \\
\text { ions } \\
(\mathrm{m} / \mathrm{z})\end{array}$ & $\mathrm{CE}(\mathrm{V})$ & & \\
\hline \multirow[t]{3}{*}{ A } & \multirow[t]{3}{*}{342.0} & 251.2 & 30 & \multirow[t]{3}{*}{$10-360$} & \multirow[t]{3}{*}{ ZDHD } \\
\hline & & 279.2 & 29 & & \\
\hline & & 235.3 & 48 & & \\
\hline \multirow[t]{3}{*}{ B } & \multirow[t]{3}{*}{427.0} & 340.1 & 24 & \multirow[t]{3}{*}{$10-440$} & \multirow[t]{3}{*}{ Z-Cys } \\
\hline & & 266.9 & 48 & & \\
\hline & & 294.9 & 35 & & \\
\hline \multirow[t]{3}{*}{$\mathrm{C}$} & \multirow[t]{3}{*}{445.1} & 324.1 & 18 & \multirow[t]{3}{*}{$10-460$} & \multirow[t]{3}{*}{$\mathrm{Z}-\mathrm{H}_{2} \mathrm{OCys}$} \\
\hline & & 251.2 & 41 & & \\
\hline & & 339.9 & 28 & & \\
\hline \multirow[t]{3}{*}{$\mathrm{D}$} & \multirow[t]{3}{*}{500.0} & 324.1 & 25 & \multirow[t]{3}{*}{$10-540$} & \multirow[t]{3}{*}{ Z-OGlu } \\
\hline & & 251.2 & 53 & & \\
\hline & & 279.1 & 50 & & \\
\hline \multirow[t]{3}{*}{$\mathrm{E}$} & \multirow[t]{3}{*}{518.0} & 251.1 & 43 & \multirow[t]{3}{*}{$10-560$} & \multirow[t]{3}{*}{ ZDHD-Glu } \\
\hline & & 324.1 & 24 & & \\
\hline & & 342.1 & 27 & & \\
\hline
\end{tabular}

CEs for product ion scans were set to $15,35,55$, and $75 \mathrm{~V}$ (see text)

$C E$ collision energy, MRM multiple reaction monitoring

analysis. Ionization was performed by ESI in positive mode under the following conditions: nebulizer gas flow rate, $3 \mathrm{~L} /$ min; heating gas flow rate, $10 \mathrm{~L} / \mathrm{min}$; drying gas flow rate, $15 \mathrm{~L} / \mathrm{min}$; interface temperature, $300{ }^{\circ} \mathrm{C}$; desolvation line temperature, $250{ }^{\circ} \mathrm{C}$; heating bloc temperature, $400{ }^{\circ} \mathrm{C}$; and interface voltage, $4 \mathrm{kV}$. The DDA mode was applied. The scan range of the trigger scan was $m / z 200-800$. Product ion spectra were acquired at CE of $35 \pm 17 \mathrm{~V}$ over $\mathrm{m} / \mathrm{z}, 10-800$. Precursor ions, fragment ions, and the corresponding formulas are listed in the supplementary information (Table S1).

\section{Glucuronidase treatment}

The urine $(50 \mu \mathrm{L})$ was mixed with $5 \mu \mathrm{L}$ of $0.1 \mathrm{~mol} / \mathrm{L}$ phosphate buffer (pH 6). Then, $5 \mu \mathrm{L}$ of $1 \mathrm{mg} / \mathrm{mL}$ glucuronidase in $10 \mathrm{mM}$ phosphate buffer was added and the mixture was incubated at $37{ }^{\circ} \mathrm{C}$ for $3 \mathrm{~h}$. To this, $0.1 \%$ formic acid-acetonitrile $(100 \mu \mathrm{L})$ was added and the mixture was centrifuged $(6800 \times g, 5 \mathrm{~min})$. The supernatant was evaporated under the stream of nitrogen at $40{ }^{\circ} \mathrm{C}$. Methanol $(25 \mu \mathrm{L})$ and water $(25 \mu \mathrm{L})$ were added to the residue in turn, and the mixture was stirred vigorously and centrifuged $(6800 \times g, 5 \mathrm{~min})$. The supernatant was transferred to a vial. An aliquot $(10 \mu \mathrm{L})$ was injected into the LC-QqQMS system. At the same time, urine extract without glucuronidase treatment $(5 \mu \mathrm{L}$ of $10 \mathrm{mM}$ buffer was added instead of the glucuronidase solution) was also prepared. The urine was extracted and analyzed in triplicate and averages of peak areas were used to evaluate the changes caused by glucuronidase treatment (Table $\mathrm{S} 2$ in the supplementary information).

Result

\section{Synthesis of hydroxyzolpidems}

$7 \mathrm{OMeZ}$ and $8 \mathrm{OBzZ}$ were synthesized via the three-component coupling reaction, which was developed in our previous study [9]. The yields were $44 \%$ and $42 \%$, for $7 \mathrm{OMeZ}$ and 8OBzZ, respectively (Fig. 2a). Demethylation of $7 \mathrm{OMeZ}$ and debenzylation of $8 \mathrm{OBzZ}$ with $\mathrm{BBr}_{3}$ afforded $7 \mathrm{OHZ}$ and $8 \mathrm{OHZ}$ in yields of $65 \%$ and $40 \%$, respectively. The ${ }^{1} \mathrm{H}$ and ${ }^{13} \mathrm{C}$ NMR spectra of $7 \mathrm{OHZ}$ hydrobromide and $8 \mathrm{OHZ}$ tosylate are shown in the supplementary information. It seemed that $7 \mathrm{OHZ}$ was not stable in non-ionic form in solution; the solution of neutralized $7 \mathrm{OHZ}$ gradually darkened within hours. However, the acid salts of $7 \mathrm{OHZ}$, such as hydrobromide, were stable even in solution at least for months at $-20{ }^{\circ} \mathrm{C}$.

We attempted to synthesize 5-hydroxyzolpidem similarly via the same coupling reaction using 6-alkoxy-2-amino5-methylpyridine, followed by the dealkylation. However, the precursor material was not commercially available. Before starting to synthesize the precursor material, we attempted the coupling reaction with commercially available 2-amino-6-methoxypyridine, in which the methyl group on the pyridine ring was absent. However, the reaction did not afford the desired product, 6-desmethyl-5-methoxyzolpidem (Fig. 2b). Therefore, we did not further attempt to synthesize 5 -hydroxyzolpidem. This result demonstrated the limitation of the coupling reaction; the alkoxy group at the 6-position of 2-aminopyridine inhibits the reaction.

\section{LC-QqQMS analysis of $70 \mathrm{HZ}$, and $80 \mathrm{HZ}$}

The product ion spectra of $7 \mathrm{OHZ}$ and $8 \mathrm{OHZ}$ with various CEs $(15,35,55$, and $75 \mathrm{~V})$ are shown in the supplementary information (Fig. S1). They were almost identical at 15 and $35 \mathrm{~V}$; fragments at $m / z, 279$ and 251 were assigned to the loss of $\mathrm{NMe}_{2}$ and $\mathrm{NMe}_{2} \mathrm{CO}$, respectively. At 55 and $75 \mathrm{~V}$, fragments that are attributed to the hydroxy-methylpyridine $(\mathrm{m} / \mathrm{z}$ 108) were observed in both $7 \mathrm{OHZ}$ and $8 \mathrm{OHZ}$. All product ion spectra of ZOL and its metabolites synthesized in our laboratory (M1-M4, 7OHZ, and 8OHZ) showed the same fragmentation patterns: (a) loss of $\mathrm{NMe}_{2}(-45 \mathrm{Da})$ and (b) loss of $\mathrm{NMe}_{2} \mathrm{CO}(-73 \mathrm{Da})$, and (c) dissociation of the pyridine moiety $(\mathrm{m} / \mathrm{z} 92$ for ZOL, M1, and M3; $\mathrm{m} / \mathrm{z} 108$ for M4, $7 \mathrm{OHZ}$, and $8 \mathrm{OHZ}$; and $\mathrm{m} / \mathrm{z}, 122$ for M2) at 55 and $75 \mathrm{~V}$.

The chromatograms obtained from the analysis of $7 \mathrm{OHZ}$ and $8 \mathrm{OHZ}$ along with $\mathrm{ZOL}$ and previously synthesized 
(a)<smiles>[X]c1c(C)cnc(N)c1[Y]</smiles><smiles>Cc1ccc(C=O)cc1</smiles>

1: $X=\mathrm{H}, Y=\mathrm{OCH}_{3}$ 2: $\mathrm{X}=\mathrm{OCH}_{2} \mathrm{C}_{6} \mathrm{H}_{5}, \mathrm{Y}=\mathrm{H}$
1) 0.1 eq pyrrolidine $100^{\circ} \mathrm{C}, 3 \mathrm{~h}$

2) 0.2 eq $\mathrm{Cu}(\mathrm{OTf})_{2}$ 0.2 eq $\mathrm{CuCl}$ 1.8 eq DMPA $80^{\circ} \mathrm{C} 3 \mathrm{~h}$ $\stackrel{\mathrm{O} O \mathrm{~h}}{\longrightarrow}$<smiles>C1CCCCCC1</smiles><smiles>[X]c1c(C)cn2c(CC(=O)N(C)C)c(-c3ccc(C)cc3)nc2c1[X]</smiles>

7OMeZ: $X=\mathrm{H}, \mathrm{Y}=\mathrm{OCH}_{3}, 44 \%$

8OBzZ: $X=\mathrm{OCH}_{2} \mathrm{C}_{6} \mathrm{H}_{5}, \mathrm{Y}=\mathrm{H}, 42 \%$

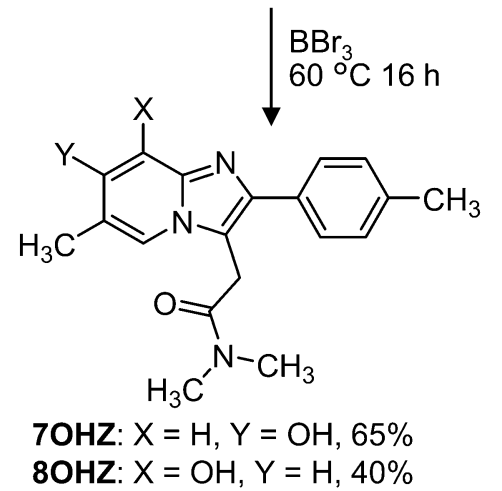

(b)<smiles>COc1cccc(N)n1</smiles>

Fig. 2 a Synthesis of 7OHZ and 8OHZ. b Attempt to synthesize a 5-methoxyzolpidem analogue

M1-M4 at concentrations of $100 \mathrm{ng} / \mathrm{mL}$ are shown in Fig. 3. The hydroxyzolpidems were clearly separated and eluted in the order of M3, 7OHZ, M4, and 8OHZ using the octadecyl silica $(\mathrm{C} 18)$ column with gradient elution of methanol - $10 \mathrm{mM}$ aqueous ammonium formate.

The extract of the urine specimen was analyzed under the same conditions, and the mass chromatograms are also shown in Fig. 3. The most intense peak among hydroxyzolpidems was assigned to $7 \mathrm{OHZ}$. The presence of $8 \mathrm{OHZ}$ was also confirmed, but its peak intensity was much lower. Peak intensities of hydroxyzolpidems were in the order of $7 \mathrm{OHZ}>\mathrm{M} 4>>8 \mathrm{OHZ}>\mathrm{M} 3$.

\section{Search for other ZOL metabolites}

We found five peaks with a fragmentation pattern similar to that of ZOL, and their precursor ions were $m / z 342,427$, 445, 500, and 518 (peaks A, B, C, D, and E, respectively). To reveal the presence of isomers for each metabolite, analysis with higher sensitivity was necessary. Therefore, MRM parameters for these metabolites were optimized using the urine extract, and analyzed the extract again in MRM mode. Mass chromatograms and product ion spectra of these peaks at various CEs are shown in Figs. 4, 5, 6, 7 and 8.

Peak A appeared at $14.5 \mathrm{~min}$ (Fig. 4). The precursor ion was $m / z, 342$, which corresponds to " $[\mathrm{ZOL}+\mathrm{H}]^{+}+\mathrm{H}_{2} \mathrm{O}_{2}$ ". In its product ion spectra at $15 \mathrm{~V}$, a fragment was observed at $m / z$ 324, indicating a facile loss of $\mathrm{H}_{2} \mathrm{O}$. Fragments of $\mathrm{m} / \mathrm{z}$ 279 and 251 were assigned to loss of $\mathrm{NMe}_{2}$ and $\mathrm{NMe}_{2} \mathrm{CO}$ from the fragment of $\mathrm{m} / \mathrm{z} 324$, respectively. The $\mathrm{m} / \mathrm{z}$ values of fragments observed at 55 and $75 \mathrm{~V}(\mathrm{~m} / \mathrm{z}, 235,207,144$, $129,108,68$, and 53) were identical to those observed in the product ion spectrum of $8 \mathrm{OHZ}$. These results indicate that this compound is a hydrated form of $8 \mathrm{OHZ}$. The results from LC-QqTOFMS analysis reinforced these assignments; the $m / z$ value of peak A $(m / z$ 342.1813, Table S1) corresponds to $[\mathrm{ZOL}+\mathrm{H}]^{+}+\mathrm{H}_{2} \mathrm{O}_{2}$, and the fragments at $\mathrm{m} / z$ 324.1705, 279.1134 , and 251.1180 corresponded to the fragments 
Fig. 3 Mass chromatograms of synthetic standards at a concentration of $100 \mathrm{ng} / \mathrm{mL}$ (above) and urine extract (below)
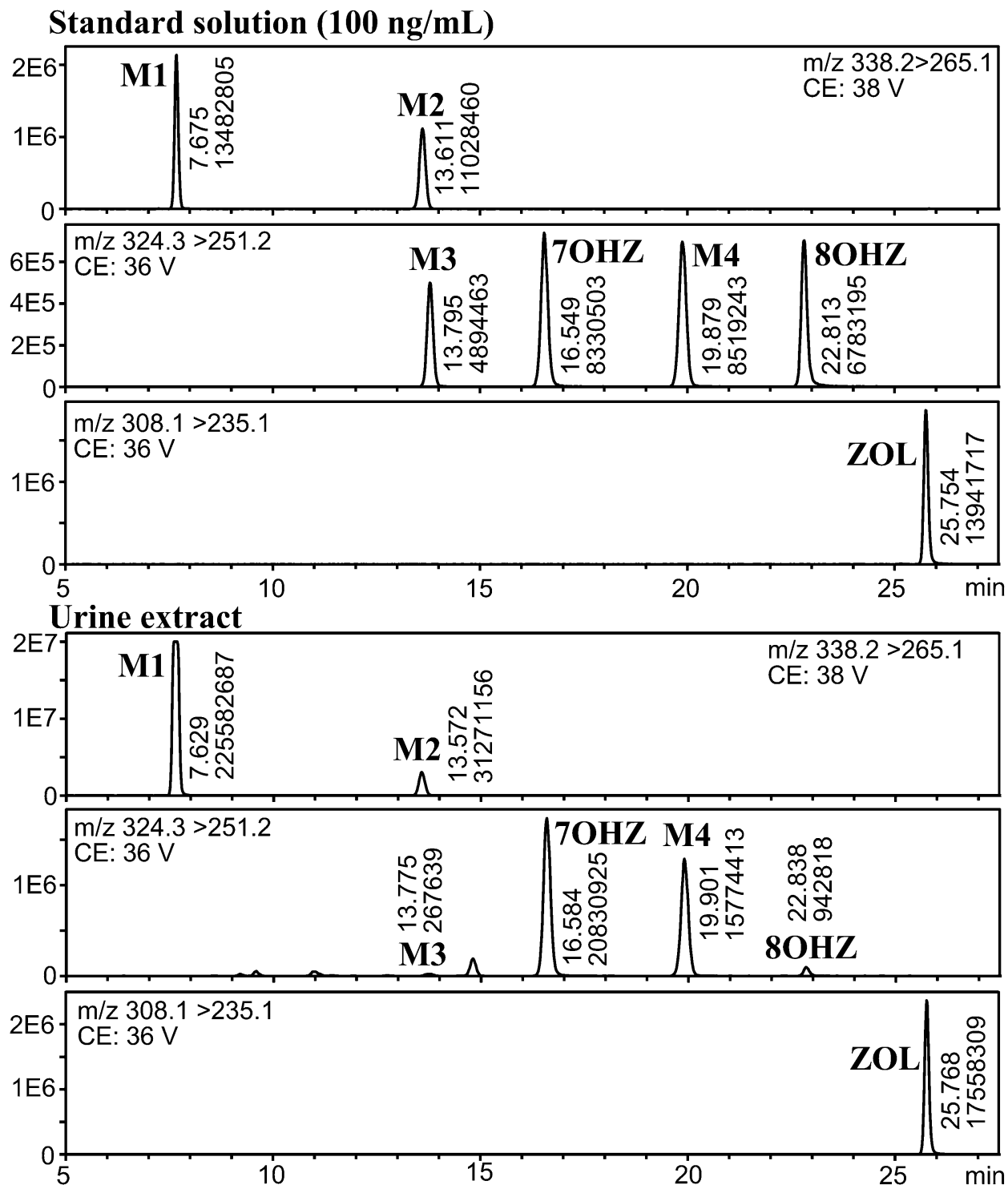

described above. Considering that this compound was formed by ZOL metabolism, the most plausible structure of peak A is ZOL dihydrodiol (ZDHD), which has two hydroxy groups at the 7- and 8-positions and a saturated $\mathrm{C}-\mathrm{C}$ bond between them, as depicted in Fig. 4. There are two possible isomers, anti-7,8-diol and syn-7,8-diol, but the stereochemistry cannot be elucidated by mass spectrometry alone.

Peak B (precursor ion: $\mathrm{m} / \mathrm{z}$ 427) appeared at $20.6 \mathrm{~min}$ (Fig. 5). Its product ion spectra show a facile loss of $87 \mathrm{Da}$ that afforded a fragment at $\mathrm{m} / \mathrm{z}, 340$, followed by the loss of $\mathrm{NMe}_{2}(\mathrm{~m} / z, 295)$ and $\mathrm{NMe}_{2} \mathrm{CO}(\mathrm{m} / z$ 267). These fragments were 32 Da higher than those of ZOL. In addition, a fragment at $m / z 124$ was observed at $75 \mathrm{~V}$, which indicated that "32 Da" was bound to the pyridine ring. The result of LC-QqTOFMS analysis revealed that the "32 Da" corresponds to one sulfur atom and the formula of this metabolite is " $\mathrm{ZOL}+\mathrm{C}_{3} \mathrm{H}_{5} \mathrm{NO}_{2} \mathrm{~S}$ ". From these observations, peak $\mathrm{B}$ can plausibly be attributed to a cysteine adduct of ZOL (Z-Cys, Fig. 5). The cysteine is bound somewhere on the pyridine ring, but its exact location could not be elucidated.

Peak C (precursor ion: $\mathrm{m} / \mathrm{z} 445$ ) appeared at $11.1 \mathrm{~min}$ (Fig. 6). Its product ion spectra revealed three fragmentation pathways. (i) A loss of water $(\mathrm{m} / \mathrm{z} 427)$ at $15 \mathrm{~V}$, followed by the formation of sulfur-bound ZOL $(\mathrm{m} / \mathrm{z}, 340,295$, and 267). This pathway is identical to that of Z-Cys. (ii) A loss of cysteine $(\mathrm{m} / \mathrm{z} 324)$ at $15 \mathrm{~V}$, followed by the same fragmentation as those of hydroxyzolpidems $(\mathrm{m} / \mathrm{z} 279$ and 251), and (iii) formation of ZOL $(\mathrm{m} / \mathrm{z} 308,263$, and 235). The result of LC-QqTOFMS analysis reinforced these assignments. From these results, this metabolite is assigned to the hydrated form of Z-Cys, that is, the cysteine adduct of dihydro(hydroxy) zolpidem ( $\left.\mathrm{Z}-\mathrm{H}_{2} \mathrm{OCys}\right)$, as depicted in Fig. 6. The exact location of the cysteine and hydroxy group, including the stereochemistry is unknown. 
Fig. 4 Mass chromatograms (above) and mass spectra (below) of peak A
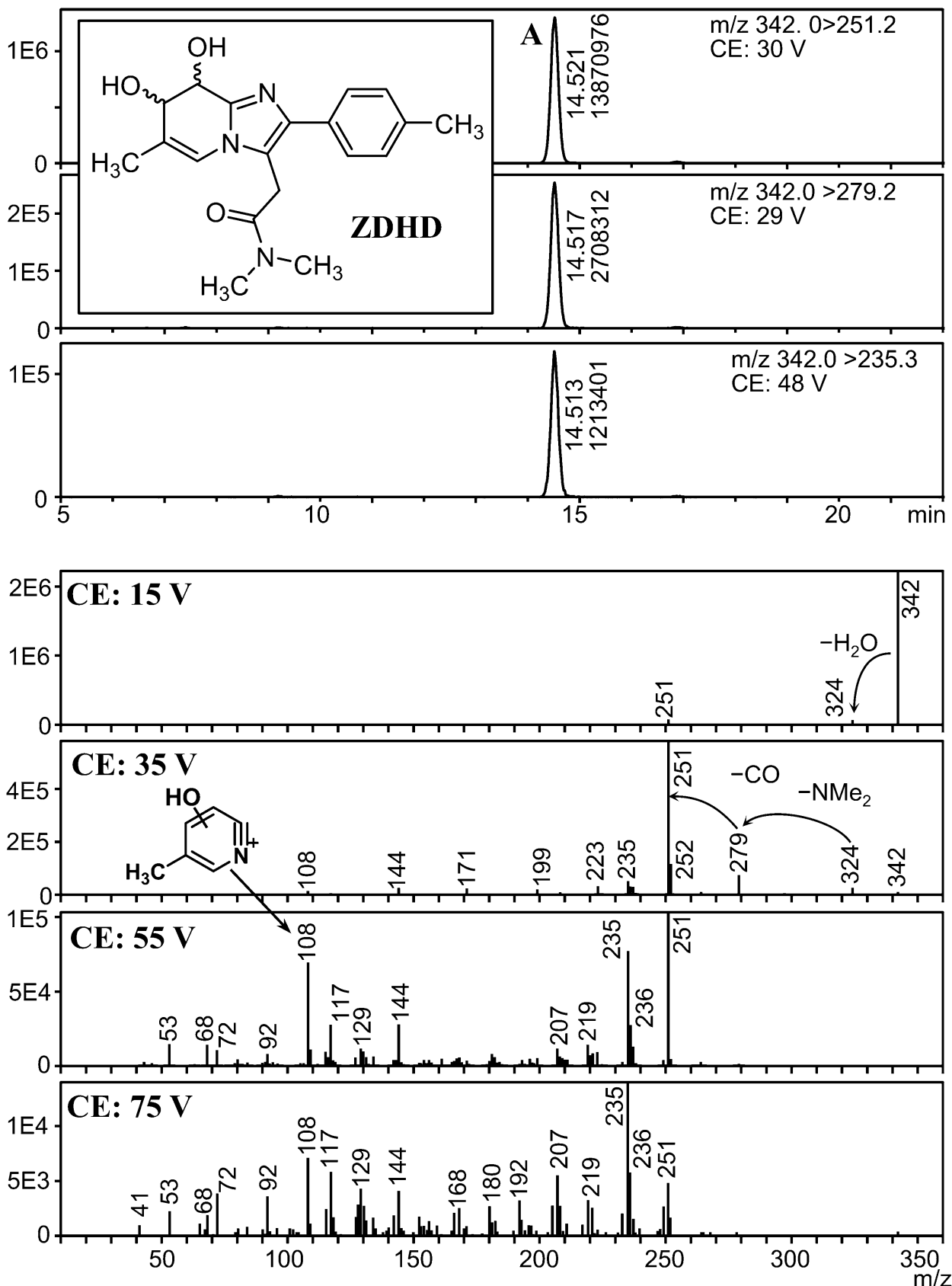

Mass chromatograms of peak D1-D5 (precursor ion: $\mathrm{m} / \mathrm{z}$ 500), and product ion spectra of the most intense peak (D3) are shown in Fig. 7. The product ion spectra indicate loss of glucuronic acid ( $-176 \mathrm{Da}, \mathrm{m} / z$ 324), and formation of the fragments identical to those of hydroxyzolpidems $(\mathrm{m} / z, 279$ and 251). In addition, the peaks D1-D5 disappeared after glucuronidase treatment, and the peak areas of the four hydroxyzolpidems (M3, M4, 7OHZ, and 8OHZ) increased (Table S2). From these results, peaks D1-D5 were assigned to glucuronides of M3, M4, 7OHZ, 8OHZ, and one more unidentified hydroxyzolpidem.
We found one more group of glucuronides. In Fig. 8, three peaks were observed on the mass chromatograms (precursor ion: $m / z$ 518, peak E1, E2, and E3). In addition, the product ion spectra of the most intense peak (E3) showed loss of glucuronide $(\mathrm{m} / \mathrm{z} 342)$, and glucuronide and water $(\mathrm{m} / \mathrm{z}, 324)$ at $15 \mathrm{~V}$. After glucuronidase treatment, peaks E1, E2, and E3 almost disappeared (peak areas less than $0.3 \%$ ), whereas the peak areas of ZDHD increased by 7.6-fold (Table S2). From these results, peak E1-E3 were assigned to glucuronides of ZDHD (ZDHDGlus). The presence of three peaks indicates ZDHD-Glus 
Fig. 5 Mass chromatograms (above) and mass spectra (below) of peak B
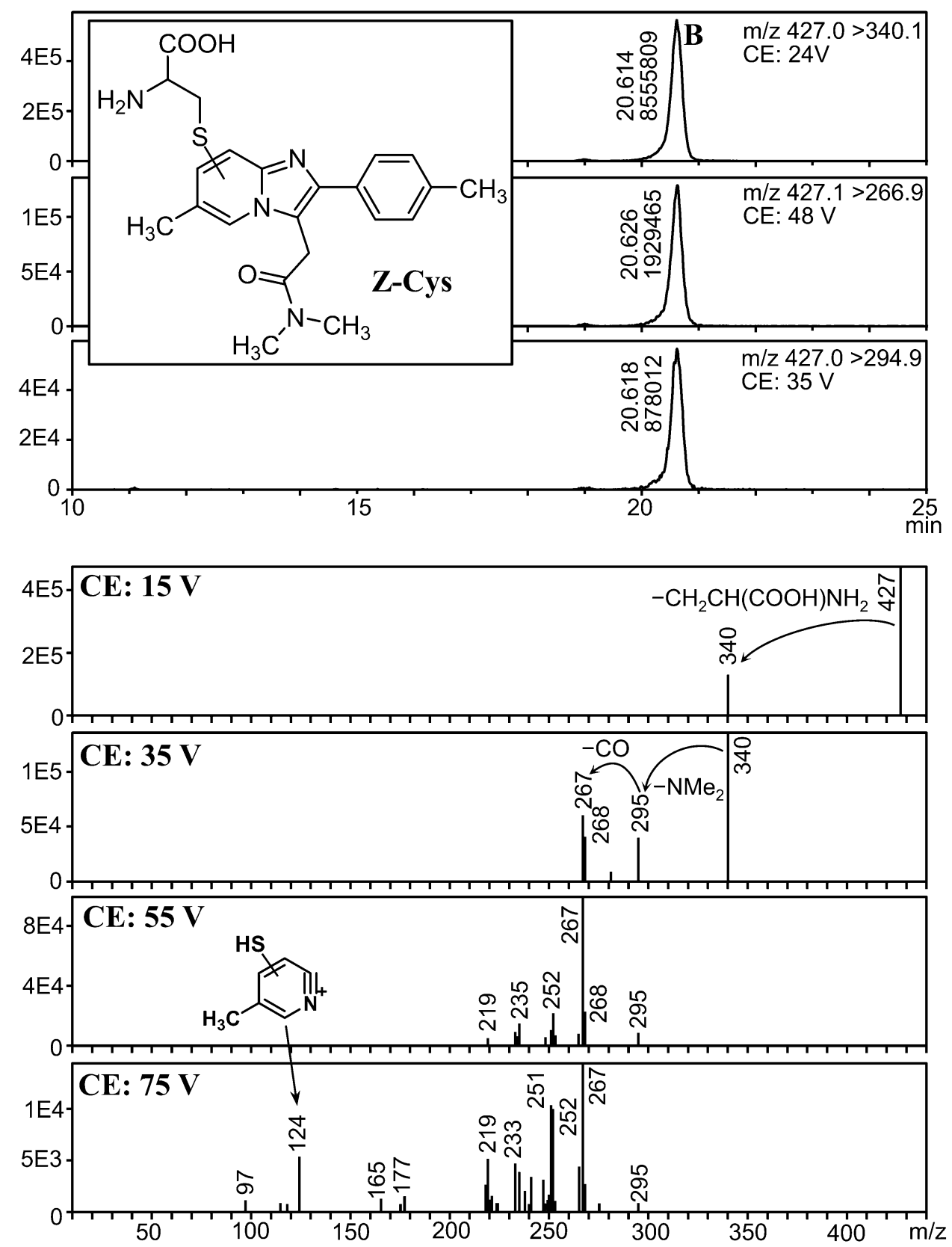

has at least three isomers. This can be explained by the presence of the two hydroxy groups and the stereochemistry of ZDHD: there are two possible isomers (syn and anti) and two enantiomers for each. For example, if ZDHD has anti geometry, ZDHD consists of two enantiomers, (7R, 8R)- and (7S, 8S)-ZDHD, which are not separable without chiral chromatography, and glucuronidation of anti-ZDHD affords four structural isomers, (7R, 8R)-ZDHD-7-glucuronide, (7R, 8R)-ZDHD8-glucuronide, (7S, 8S)-ZDHD-7-glucuronide, and (7S, 8S)-ZDHD-8-glucuronide.

\section{Discussion}

\section{Synthesis and analysis of $70 \mathrm{HZ}$ and $80 \mathrm{HZ}$}

We have successfully synthesized four hydroxyzolpidems (M3, M4, 7OHZ, and 8OHZ) so far. Their product ion spectra were almost identical, meaning that chromatographic separation was necessary. Their peaks were clearly separated by the optimized conditions in this study and were successfully assigned as a result. 
Fig. 6 Mass chromatograms (above) and mass spectra (below) of peak $\mathrm{C}$
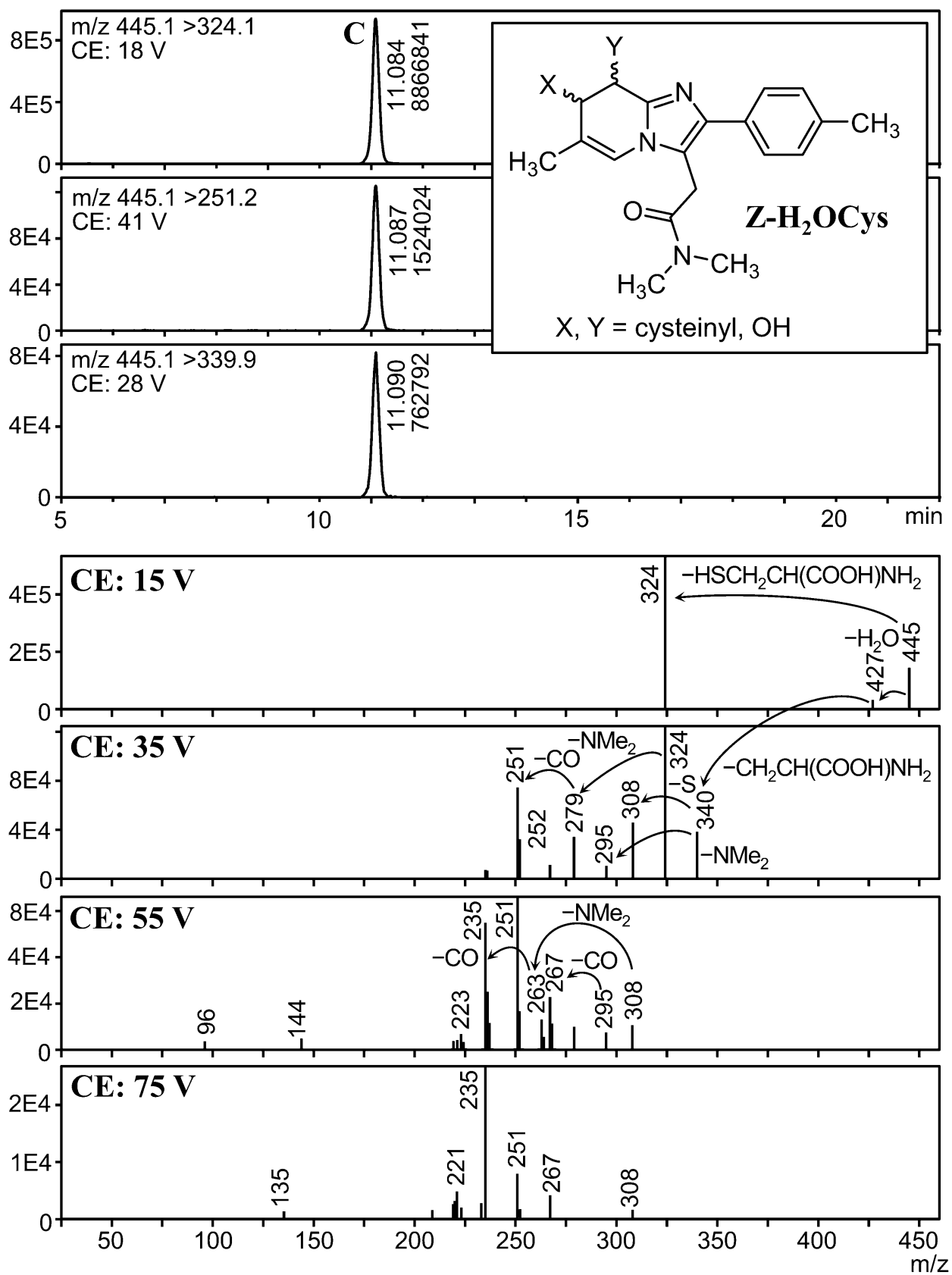

The presence of $7 \mathrm{OHZ}$ and $8 \mathrm{OHZ}$ in human urine obtained from the deceased was confirmed, and the peak intensity of $7 \mathrm{OHZ}$ was the highest among the hydroxyzolpidems. The presence of the hydroxyzolpidem with a hydroxy group on the pyridine ring was first reported by Thénot et al. [10], but the exact location of the hydroxy group was not determined. The structure of this metabolite was identified as $7 \mathrm{OHZ}$ for the first time in the present study by comparison with synthetic standards. Thénot et al. also reported that the ratio of the metabolites eliminated in human urine and feces were $51.5 \%, 11.5 \%$, and $10.1 \%$ for M1, M2, and "hydroxylation on the imidazopyridine ring", respectively.
In the present study, the peak intensity of M1 was strongest, that of M2 was the second highest, and 7OHZ followed. These results suggest that the ratio of metabolites is approximately same between the previous study and this study.

\section{Search for novel metabolites and proposal of novel metabolic pathways}

Many studies have focused on the analysis of ZOL metabolites in human body fluids [3, 10-15], but to our knowledge, ZDHD, Z-Cys, and Z- $\mathrm{H}_{2} \mathrm{OCys}$ were found for the first time in this study. We analyzed the urine sample obtained from a 
Fig. 7 Mass chromatograms of peak D1-D5 (above) and mass spectra of peak D3 (below)
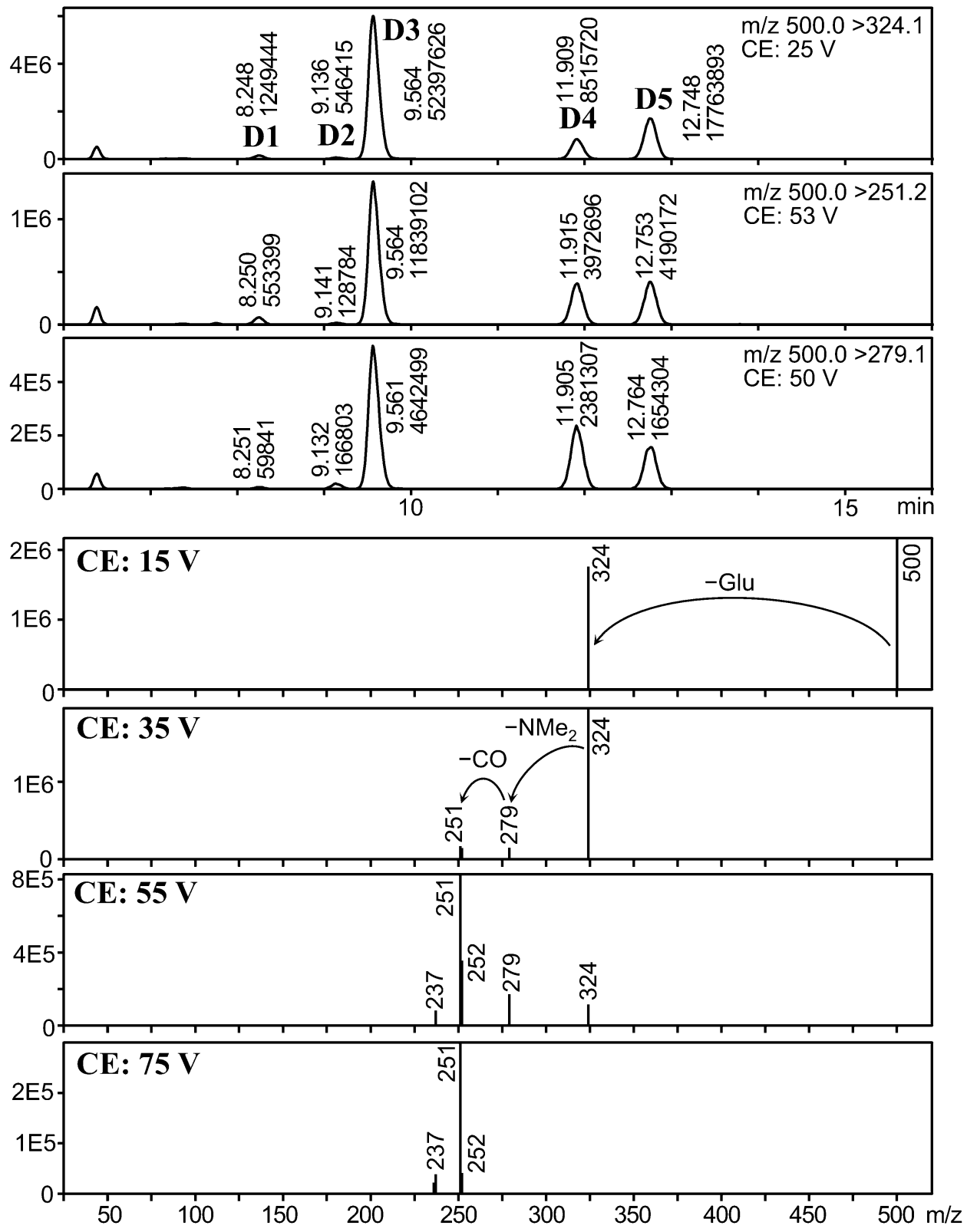

deceased man who was elderly (in his eighties) and had been prescribed ZOL 2 weeks before his death. The clearance of $\mathrm{ZOL}$ is reported to be lower in the elderly than in young adults, resulting in higher maximum blood concentration and longer elimination half-life [16]. Therefore, ZOL had likely stayed in the deceased's body longer than it would have in a young adult, which resulted in the accumulation of minor metabolites, such as ZDHD, Z-Cys, and Z- $\mathrm{H}_{2} \mathrm{OCys}$.

Concerning glucuronides, Rossi et al. investigated urinary metabolites after intake of $10 \mathrm{mg}$ ZOL and found that hydroxyzolpidem and ZOL carboxylic acids are partially glucuroconjugated [11]. In our study, we revealed the presence of glucuronides of hydroxyzolpidems, which agreed with Rossi's result, whereas we could not find any acyl glucuronides. Our result from the glucuronidase treatment experiment also indicated that glucuronides of M1 and M2 were not present in the sample. The acyl glucuronides of M1 and M2 probably decomposed during the time between death and autopsy, because acyl glucuronides are known to be instable metabolites and easily hydrolyzed to carboxylic acids [17].

To postulate a novel metabolic pathway, we referred to the metabolism of alpidem, which has the same imidazo[1,2- $\alpha]$ pyridine structure [8]. The metabolic pathway of alpidem includes the formation of an epoxide at $\mathrm{C}-\mathrm{C}$ bond between the 7 - and 8-position as an intermediate. The epoxide reacts with glutathione to afford the glutathione adduct of dihydro(hydroxy)alpidem, followed by dehydration that 
Fig. 8 Mass chromatograms of peak E1-E3 (above) and mass spectra (below) of peak E3
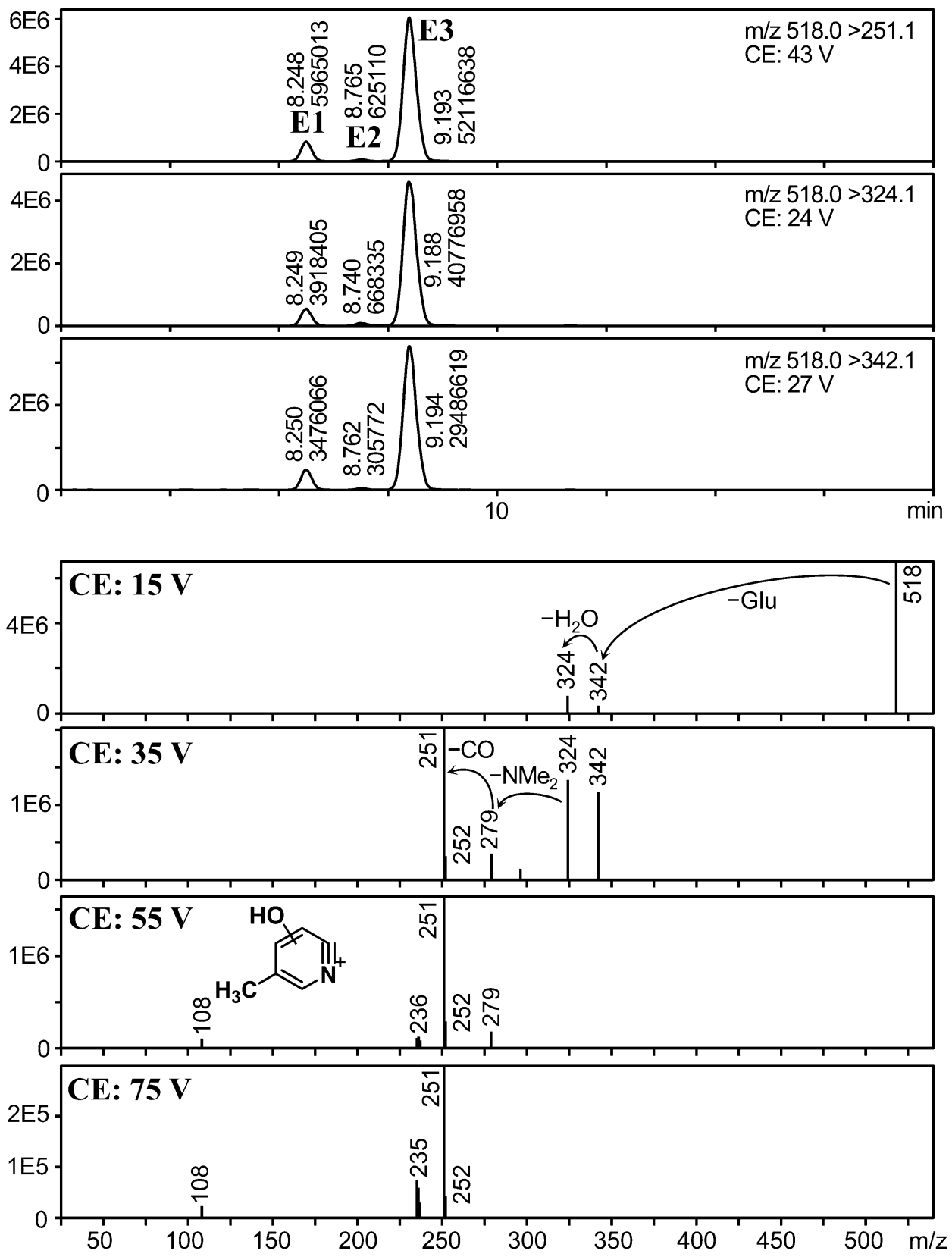

affords glutathione adducts of alpidem. We present new metabolic pathways of ZOL, which forms ZDHD, Z-Cys, $\mathrm{Z}-\mathrm{H}_{2} \mathrm{OCys}, 7 \mathrm{OHZ}$, and $8 \mathrm{OHZ}$, as illustrated in Fig. 9. First, oxidation at the $\mathrm{C}-\mathrm{C}$ double bond between the 7- and 8-positions forms ZOL epoxide as an intermediate (a). Reaction of the epoxide with water affords ZDHD (b). Proton migration in the epoxide affords $7 \mathrm{OHZ}$ and $8 \mathrm{OHZ}$ (c). Reaction of the epoxide with glutathione affords glutathione adduct of dihydro(hydroxy)zolpidem, which was not detected in this study (d). Elimination of amino acids from the glutathione adduct forms $\mathrm{Z}-\mathrm{H}_{2} \mathrm{OCys}$ (e). Dehydration from $\mathrm{Z}-\mathrm{H}_{2} \mathrm{OCys}$ affords Z-Cys (f). We could not find the glutathione adduct of dihydro(hydroxy)zolpidem, which is the key metabolite in this pathway. This was probably because this metabolite is not eliminated in urine before further metabolism proceeds.

Alpidem was withdrawn from the market worldwide, because it causes severe liver damage [18]. One of the reasons for this is that the epoxide intermediate acts as a reactive metabolite, which was supported by the results showing that a high concentration of alpidem $(500 \mu \mathrm{M})$ in isolated rat hepatocytes induces glutathione depletion, whereas the same concentration of ZOL causes only moderate glutathione depletion [19]. The results of the present study indicate that there is a metabolic pathway of ZOL that consumes glutathione, but the pathway involves only a small fraction of ZOL administered. 
Fig. 9 Proposed metabolic pathway of ZOL based on the findings in this study

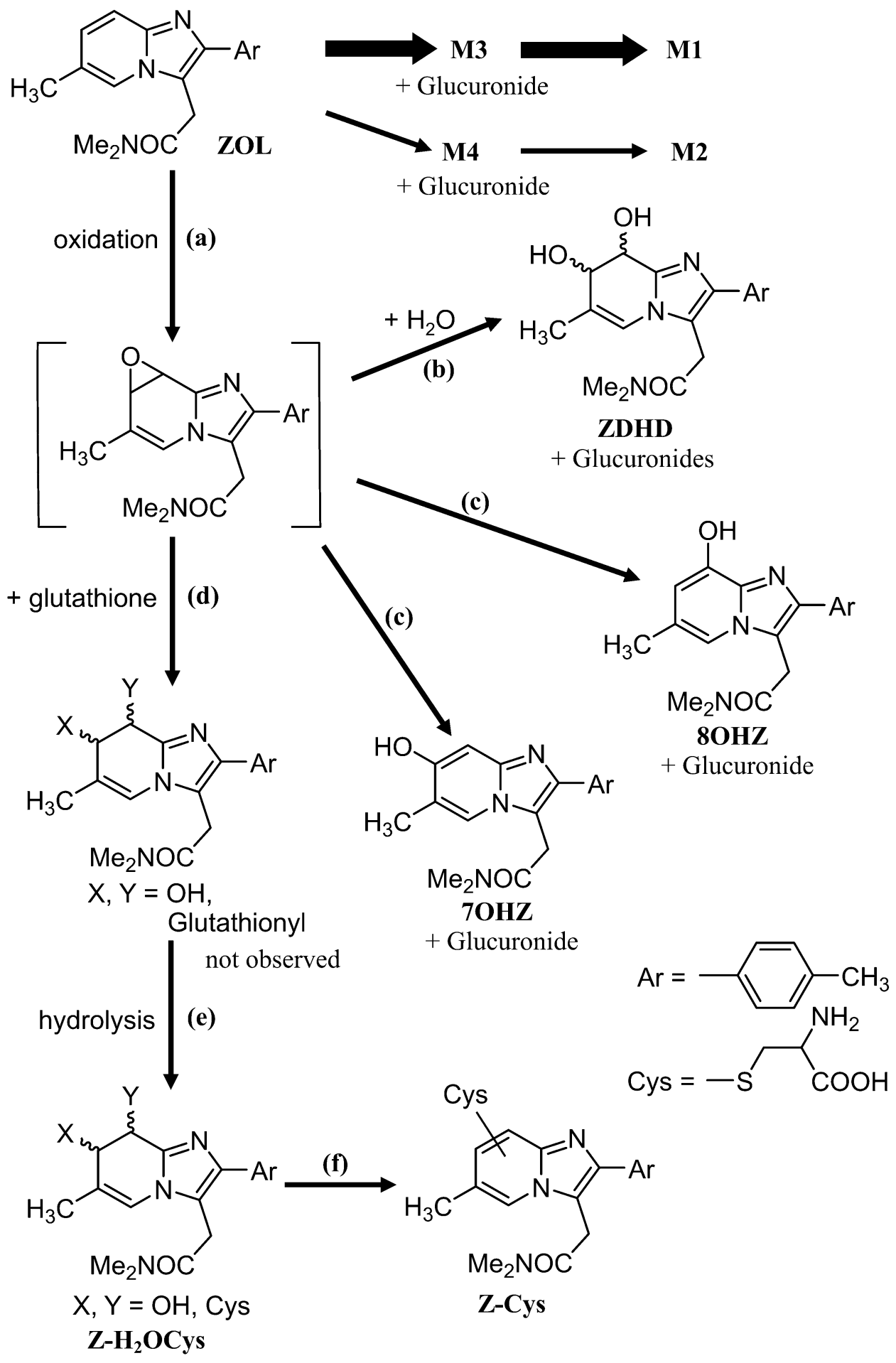

As reported in many studies, the major metabolite of ZOL in urine is M1. Detection of ZOL and M1 is enough proof for ZOL misuse. However, this study revealed the presence of several novel metabolites in urine that are detectable using LC-MS/MS. These metabolites are formed from a small fraction of ZOL intake but are expected to show different characteristics in the excretion and distribution in human body; therefore, further studies into these metabolites from a toxicological perspective are awaited, for example, quantification of these metabolites in urine obtained from various type of subjects (age, sex, etc.). We are currently trying to develop a method for simultaneously quantifying ZOL, M1-M4, 7OHZ, and 8OHZ in urine, including validation of the method and its application to autopsy samples. 


\section{Conclusions}

We successfully synthesized $7 \mathrm{OHZ}$ and $8 \mathrm{OHZ}$, and their presence in postmortem urine was confirmed. The peak intensity of M1 was predominant, and those of hydroxyzolpidems were in the order of $7 \mathrm{OHZ}>\mathrm{M} 4>>8 \mathrm{OHZ}>\mathrm{M} 3$. We also searched for other urinary ZOL metabolites and found ZDHD and its glucuronides (ZDHD-Glus), Z-Cys, Z-H ${ }_{2} \mathrm{OCys}$, and Z-OGlus. The presence of these metabolites led to identification of novel metabolic pathways, including epoxide formation between the 7- and 8-positions as an intermediate.

Supplementary Information The online version contains supplementary material available at https://doi.org/10.1007/s11419-021-00611-9.

Acknowledgements This work was supported by JSPS KAKENHI Grant Numbers 24790646, 16K09221, and 20K10566. We are deeply grateful to Mr. Takahiro Goda (Shimadzu Co.) for assistance with structural elucidation of the novel metabolites using LC-QqTOFMS, to Dr. Ryo Takita and Ms. Mio Takagi (Graduate School of Pharmaceutical Sciences, The University of Tokyo) for assistance with the NMR measurements and elemental analysis, and to Dr. Yuko Kazui (National Research Institute of Police Science) for assistance with the NMR measurements.

\section{Declarations}

Conflict of interest The authors declare that they have no conflict of interest.

Ethical approval The use of urine samples obtained from an autopsy was approved by the Human Ethics Committee of Nippon Medical School (approval number: 26-13).

Open Access This article is licensed under a Creative Commons Attribution 4.0 International License, which permits use, sharing, adaptation, distribution and reproduction in any medium or format, as long as you give appropriate credit to the original author(s) and the source, provide a link to the Creative Commons licence, and indicate if changes were made. The images or other third party material in this article are included in the article's Creative Commons licence, unless indicated otherwise in a credit line to the material. If material is not included in the article's Creative Commons licence and your intended use is not permitted by statutory regulation or exceeds the permitted use, you will need to obtain permission directly from the copyright holder. To view a copy of this licence, visit http://creativecommons.org/licenses/by/4.0/.

\section{References}

1. Forsman M, Nyström I, Roman M, Berglund L, Ahlner J, Kronstrand R (2009) Urinary detection times and excretion patterns of flunitrazepam and its metabolites after a single oral dose. J Anal Toxicol 33(8):491-501. https://doi.org/10.1093/ jat/33.8.491

2. Tsujikawa K, Kuwayama K, Miyaguchi H, Kanamori T, Iwata Y, Inoue H, Kishi T (2005) Urinary excretion profiles of two major triazolam metabolites, alpha-hydroxytriazolam and 4-hydroxytriazolam. J Anal Toxicol 29(4):240-243. https://doi. org/10.1093/jat/29.4.240

3. Feng X, Chen H, Xiang P, Shen M (2019) Zolpidem and zolpidem phenyl-4-carboxylic acid pharmacokinetics in oral fluid after a single dose. Drug Test Anal 11(7):1076-1082. https:// doi.org/10.1002/dta.2594

4. Wen B, Zhu M (2015) Applications of mass spectrometry in drug metabolism: 50 years of progress. Drug Metab Rev 47(1):71-87. https://doi.org/10.3109/03602532.2014.1001029

5. Prakash C, Shaffer CL, Nedderman A (2007) Analytical strategies for identifying drug metabolites. Mass Spectrom Rev 26(3):340-369. https://doi.org/10.1002/mas.20128

6. Yamaguchi K, Goda T, Yamaki S, Ohno Y (2015) Structural analysis of quazepam metabolites in bile by ion trap time-offlight mass spectrometry. Forensic Sci Int 256:7-16. https://doi. org/10.1016/j.forsciint.2015.07.016

7. Food and Drug Administration (2013) Some sleep drugs can impair driving. https://www.fda.gov/consumers/consumer-updat es/some-sleep-drugs-can-impair-driving. Accessed 23 Aug 2021

8. Durand A, Thénot JP, Bianchetti G, Morselli PL (1992) Comparative pharmacokinetic profile of two imidazopyridine drugs: zolpidem and alpidem. Drug Metab Rev 24(2):239-266. https:// doi.org/10.3109/03602539208996294

9. Yamaguchi K, Miyaguchi H, Hirakawa K, Ohno Y, Kanawaku Y (2021) Qualitative analysis of zolpidem and its metabolites M-1 to M-4 in human blood and urine using liquid chromatographytandem mass spectrometry. Forensic Toxicol 39(1):134-145. https://doi.org/10.1007/s11419-020-00551-w

10. Thénot JP, Hermann P, Durand A, Burke JT, Allen J, Garrigou D, Vajta S, Albin H, Thébault JJ, Olive G, Warrington SJ (1988) Pharmacokinetics and metabolism of zolpidem in various animal species and in humans. Imidazopyridines in sleep disorders: a novel experimental and therapeutic approach. Raven Press, New York, pp 139-153

11. Strano Rossi S, Anzillotti L, Castrignanò E, Frison G, Zancanaro F, Chiarotti M (2014) UHPLC-MS/MS and UHPLCHRMS identification of zolpidem and zopiclone main urinary metabolites and method development for their toxicological determination. Drug Test Anal 6(3):226-233. https://doi.org/ 10.1002/dta. 1470

12. Schwope DM, DePriest A, Black DL, Caplan YH, Cone EJ, Heltsley R (2014) Determining zolpidem compliance: urinary metabolite detection and prevalence in chronic pain patients. J Anal Toxicol 38(8):513-518. https://doi.org/10.1093/jat/bku068

13. Shi Y, Xiang P, Shen B, Shen M (2012) A rapid and accurate UPLC/MS/MS method for the simultaneous determination of zolpidem and its main metabolites in biological fluids and its application in a forensic context. J Chromatogr B Anal Technol Biomed Life Sci 911:140-146. https://doi.org/10.1016/j.jchro mb.2012.10.018

14. Hasegawa K, Wurita A, Nozawa H, Yamagishi I, Minakata K, Watanabe K, Suzuki O (2018) Fatal zolpidem poisoning due to its intravenous self-injection: postmortem distribution/redistribution of zolpidem and its predominant metabolite zolpidem phenyl-4-carboxylic acid in body fluids and solid tissues in an autopsy case. Forensic Sci Int 290:111-120. https://doi.org/10. 1016/j.forsciint.2018.06.044

15. Ascalone V, Flaminio L, Guinebault P, Thénot JP, Morselli PL (1992) Determination of zolpidem, a new sleep-inducing agent, and its metabolites in biological fluids: pharmacokinetics, drug metabolism and overdosing investigations in humans. J Chromatogr 581(2):237-250. https://doi.org/10.1016/0378-4347(92) 80277-w 
16. Olubodun JO, Ochs HR, von Moltke LL, Roubenoff R, Hesse LM, Harmatz JS, Shader RI, Greenblatt DJ (2003) Pharmacokinetic properties of zolpidem in elderly and young adults: possible modulation by testosterone in men. Br J Clin Pharmacol 56(3):297-304. https://doi.org/10.1046/j.0306-5251.2003. 01852.x

17. Patel SR (2020) Bioanalytical challenges and strategies for accurately measuring acyl glucuronide metabolites in biological fluids. Biomed Chromatogr 34(1):e4640. https://doi.org/10. 1002/bmc.4640

18. World Health Organization (1994) WHO drug information. Vol 8 , issue 2, p 65. World Health Organization, Genova
19. Berson A, Descatoire V, Sutton A, Fau D, Maulny B, Vadrot N, Feldmann G, Berthon B, Tordjmann T, Pessayre D (2001) Toxicity of alpidem, a peripheral benzodiazepine receptor ligand, but not zolpidem, in rat hepatocytes: role of mitochondrial permeability transition and metabolic activation. J Pharmacol Exp Ther 299(2):793-800

Publisher's Note Springer Nature remains neutral with regard to jurisdictional claims in published maps and institutional affiliations. 